\section{Isolation, Characterization, and Management of Colletotrichum spp. Causing Anthracnose on Lucky Bamboo (Dracaena sanderiana)}

\author{
Kalpana Sharma \\ University of Florida, IFAS, Department of Plant Pathology, 1453 Fifield \\ Hall, Gainesville, FL 32611
}

\author{
Joyce L. Merritt \\ Natural Sciences Department, Santa Fe College, 3000 NW 83rd Street, \\ Gainesville, FL 32606
}

\author{
Aaron Palmateer \\ University of Florida, IFAS, Department of Plant Pathology, Tropical \\ Research and Education Center, University of Florida, 18905 S.W. 280 \\ Street, Homestead, FL 33031

\section{Erica Goss} \\ University of Florida, IFAS, Department of Plant Pathology, 1453 Fifield \\ Hall, Gainesville, FL 32611; and University of Florida, Emerging Pathogens \\ Institute, Gainesville, FL 32611
}

\section{Matthew Smith \\ University of Florida, IFAS, Department of Plant Pathology, 1453 Fifield Hall, Gainesville, FL 32611}

Tim Schubert

Florida Department of Agriculture and Consumer Services, Division of Plant Industry, 1911 S.W. 34th Street, Gainesville, FL 32608

\section{Robert S. Johnson}

U.S. Department of Agriculture, Animal and Plant Health Inspection Service, Plant Protection and Quarantine, 4700 River Road, Riverdale, MD 20737

Ariena H.C. van Bruggen ${ }^{1}$

University of Florida, IFAS, Department of Plant Pathology, 1453 Fifield Hall, Gainesville, FL 32611; and University of Florida, Emerging Pathogens Institute, Gainesville, FL 32611

Additional index words. Colletotrichum dracaenophilum, Dracaena marginata, emerging pathogens, fungicide, hot water treatment, red-edged dracaena

Abstract. International trade in ornamental plants has increased worldwide. Dracaena is the genus most frequently imported into the United States and many pests and pathogens currently not in the United States could be imported with Dracaena plant materials. In 2009, lucky bamboo (Dracaena sanderiana) with anthracnose symptoms was found in Florida. The associated fungus, putative Colletotrichum dracaenophilum, is considered a reportable pathogen that originated from Asia. Imported $D$. sanderiana plants with anthracnose symptoms were collected from a nursery in south Florida in 2011 and retail stores in north Florida in 2012 and 2013. Five isolates of Colletotrichum spp. were isolated from symptomatic $D$. sanderiana plants and Koch's postulates were fulfilled for the first time. Polymerase chain reaction was performed on the internal transcribed space (ITS) and $28 \mathrm{~S}$ rDNA regions of three original isolates and re-isolates and these sequences were compared with sequences of Colletotrichum spp. in GenBank. Sequence analysis indicated that the Colletotrichum isolates obtained from $D$. sanderiana in Florida belonged to $C$. dracaenophilum or the $C$.gloeosporioides species complex. Latent infections on healthy-looking lucky bamboo developed anthracnose lesions within 2 to 3 months. The reaction of several Dracaena species and varieties to the two Colletotrichum species was tested. Colletotrichum dracaenophilum caused the most severe disease on lucky bamboo, whereas one isolate of the $C$. gloeosporioides species complex was least pathogenic to all of the Dracaena spp. and varieties. Hot water treatments were not effective at controlling latent infections, but application of Azoxystrobin at $0.075 \mathrm{~g}$ a.i./L significantly reduced anthracnose development on both latently infected and inoculated lucky bamboo plants.
International trade in ornamental plants has increased worldwide over the last decade. All imported plants and plant propagative materials enter the United States through a U.S. port of entry such as a U.S. Department of Agriculture, Animal and Plant Health Inspection Service (USDA-APHIS) plant inspection station or a Customs and Border Patrol station, but most are not inspected. Approximately 1.2 billion ornamental plants were imported into the United States in 2010 and $\approx 863$ million $(\approx 71 \%)$ of these were processed through the USDA-APHIS Miami Plant Inspection Station (MIA) (calculated from the USDA-AQAS internal database). As a result of the large volume of plants processed at the MIA, only $2 \%$ of the 863 million imported plants were visually inspected. Thus, Florida is a major conduit for receiving plant materials that may be carrying diseases and pests from their country of origin (Merritt et al., 2012). Several plant pathogens entered the United States for the first time through Florida. Examples include Puccinia hemerocallidis, the causal agent of daylily rust introduced in 2000 (Buck and Ono, 2012), and Ralstonia solanacearum race 3 , biovar 2 , introduced on geranium cuttings in 2003 (Momol, 2006).

Dracaena was the ornamental plant genus most frequently imported into the United States between 2005 and 2009 (Liebhold et al., 2012). This genus consists of $\approx 40$ different species, including $D$. sanderiana Sander ex Mast. (lucky bamboo) and $D$. marginata Lam. (red-edged dracaena). In a survey conducted in 2011, Merritt et al. (2012) found that among ornamental nurseries in Florida participating in the U.S.-Canadian Greenhouse Certification Program, Dracaena species were most frequently exported to Canada, and most of these plants were produced from imported cuttings. Because of the high numbers of Dracaena cuttings that are imported into the United States and exported as potted plants to Canada, it is crucial to be vigilant about potential pests and pathogens on imported cuttings.

Several diseases are common on Dracaena species in the United States and in Florida. These include fungal diseases such as anthracnose (Colletotrichum spp.), Botrytis blight, and fusarium stem rot as well as bacterial diseases such as Erwinia leaf rot and stem spot (Daughtrey and Chase, 1992). In Florida, 86 diseases have been reported on Dracaena spp. Of these 86 diseases, seven are bacterial, one is viral, and 78 are fungal (Alfieri et al., 1994), yet there are many potential pests and pathogens currently not in the United States that could potentially be imported with Dracaena plant materials.

In 2009, a lucky bamboo plant (Dracaena sanderiana) with anthracnose symptoms was collected from a grocery store in Florida. The associated fungus was identified as Colletotrichum dracaenophilum (<http://www. freshfromflorida.com/Divisions-Offices/ Plant-Industry/Plant-Industry-Publications/ Tri-ology-FDACS-DPI/Volume-48-Number1-January-February-2009>), which has not yet 
been reported in the scientific literature for Florida or anywhere else in the United States. The pathogen was thought to have been introduced into Florida on lucky bamboo propagation material from Asia. On 23 Mar. 2012, a shipment from a Canadian nursery of lucky bamboo with anthracnose symptoms was intercepted by the Customs and Border Patrol at the U.S. port of entry in Blaine, WA. Again, C. dracaenophilum was associated with this disease (Balaam, personal communication) and is now considered a reportable pathogen of lucky bamboo by USDA-APHIS (Customs and Border Patrol, 2012). In addition to $C$. dracaenophilum, members of the Colletotrichum gloeosporioides species complex might be able to infect lucky bamboo, because this pathogen can attack many different plant hosts.

In Spring 2012 and 2013, lucky bamboo plants (D. sanderiana) were observed in retail stores in Gainesville, FL, with typical anthracnose symptoms. These plants had beige lesions surrounded by a dark brown border on the stalk of the plants, and these later became necrotic and spread to the entire stalk. Numerous black fruiting bodies (acervuli) containing typical Colletotrichum conidia and setae were visible within the lesions (Fig. 1a), and several leaves had wilted and abscised from the plants. According to store personnel, healthy-looking plants developed symptoms $\approx 2$ weeks after arriving at the stores, suggesting that plants were already infected when they arrived in the United States but were asymptomatic. Although C. dracaenophilum had been previously isolated from a lucky bamboo plant in Florida (<http://www. freshfromflorida.com/Divisions-Offices/ Plant-Industry/Plant-Industry-Publications/ Tri-ology-FDACS-DPI/Volume-48-Number1-January-February-2009>), Koch's postulates were not performed. Moreover, it was not demonstrated unequivocally that asymptomatic plants could carry the pathogen, and methods of control were not tested.

Data on methods to control or eliminate infections from symptomless Dracaena cuttings are lacking. One potential approach to reduce latent infection is heat treatment, which significantly reduces seed infection by several other pathogens. For example, both dry heat and hot water treatments substantially reduce or eliminate Fusarium graminearum from wheat seed (Clear et al., 2002) and Cladosporium variabile and Verticillium dahliae from spinach seed ( $\mathrm{du}$ Toit and Hernandez-Perez, 2005). Besides heat treatment, fungicide applications could eliminate

Received for publication 31 Dec. 2013. Accepted for publication 13 Feb. 2014.

This work was funded through a grant from the U.S. Department of Agriculture, Animal and Plant Health Inspection Service "Quality assessment of the U.S. Greenhouse Certification Program."

We thank Delray Plants, Inc. in Venus, FL, for donating the lucky bamboo (Dracaena sanderiana) plants.

${ }^{1}$ To whom reprint requests should be addressed; e-mail ahcvanbruggen@ufl.edu.
Colletotrichum in symptomless but infected rooted cuttings.

Much of the Colletotrichum research in recent years has been dedicated to elucidating the etiology of diseases caused by Colletotrichum spp. and the population dynamics of these pathogens. Research has emphasized differentiation of the species of Colletotrichum on each host and determining their role in producing the observed symptoms. It is common to find multiple hosts affected by a single species and multiple species of Colletotrichum infecting a single host (Peres et al., 2005; Prihastuti et al., 2009; Shivas and Tan, 2009). However, until now, it has not been clear whether there is variation in aggressiveness of different strains of Colletotrichum spp. and in susceptibility of different Dracaena species and cultivars to Colletotrichum spp.

Therefore, the objectives of this study were to 1) isolate Colletotrichum from lucky bamboo with anthracnose symptoms; 2) perform Koch's postulates with the isolated strains; 3) genetically identify the isolated strains and compare them with previously studied Colletotrichum strains; 4) determine variation in aggressiveness of different strains of Colletotrichum spp. on different Dracaena species and cultivars; 5) study the effects of hot water treatments on symptomless lucky bamboo planting material; and 6) test fungicides for the control of Colletotrichum in asymptomatic but infected rooted cuttings as well as inoculated plants.

\section{Materials and Methods}

Isolations from lucky bamboo. Isolations were made from symptomatic stalk tissue of two lucky bamboo (D. sanderiana) plants collected from an ornamental plant producer in south Florida in Aug. 2011 (isolate 1) and from two stores (A and B) in Gainesville, FL, in Feb. and Mar. 2012 (isolates 2 and 3) (Table 1). A third set of isolations was made from symptomatic lucky bamboo plants from the same stores (A and B) in Gainesville, FL, in Apr. 2013 (isolates 4 and 5) (Table 1). Diseased lesions were inspected under dissecting and compound microscopes for the presence of acervuli and setae. Stem tissue containing lesions and acervuli was surfacesterilized with a $10 \%$ bleach solution and washed in deionized water. Pure cultures were obtained by transferring acervuli from surface-sterilized symptomatic stalks onto plates of acidified ( $\mathrm{pH} 4.5$ ) potato dextrose agar (PDA) (Difco Laboratories, Detroit, $\mathrm{MI})$. Colony shape and color were observed on 7-d-old cultures grown on PDA plates. Mycelial growth, acervuli, and spores were inspected under the compound microscope. Spore sizes were measured on 50 spores per isolate. One isolate of the $C$. gloeosporioides species complex and two isolates suspected to be $C$. dracaenophilum were kept for pathogenicity tests in 2012 and 2013. Single-spore cultures were prepared and maintained on acidified PDA. Only single-spore cultures were used in all of the experiments.

Pathogenicity tests and re-isolation. Healthy-looking bare-rooted lucky bamboo stems (10 cm long), imported from China, and donated by Delray Plants in Venus, FL, were used for pathogenicity tests. Single cuttings were planted in greenhouse potting mix in $10-\mathrm{cm}$-diameter pots. The potting mix consisted of $45 \%$ Canadian sphagnum peatmoss, $30 \%$ processed pine bark, $15 \%$ vermiculite, $10 \%$ perlite, starter nutrients, wetting agent, and dolomitic limestone (Conrad Fafard, Inc., Agawam, MA). Two sets of experiments were conducted with the following isolates: 1) one putative C. gloeosporioides isolate (isolate 1) plus two putative $C$. dracaenophilum isolates (isolates 2 and 3 ) in 2012; and 2) two putative $C$. dracaenophilum isolates (isolates 4 and 5) in 2013. In both sets of experiments, 10-d-old single-spore cultures grown on acidified PDA were used to inoculate lucky
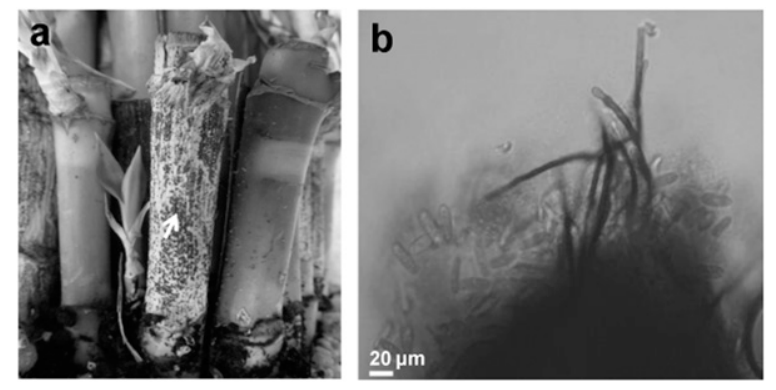

Fig. 1. (a) Lucky bamboo plants with typical anthracnose symptoms and numerous black fruiting bodies (acervuli) observed in retail stores in Gainesville, FL, and (b) a portion of an acervulus containing typical Colletotrichum conidia and setae under the compound microscope.

Table 1. Location, source, date of isolations, isolate numbers, and species of Colletotrichum identified in this study.

\begin{tabular}{llcccl}
\hline Location & City & Source & Month/year & Isolate & Colletotrichum spp. \\
\hline South Florida & Miami & Nursery & $8 / 2011$ & 1 & C. gloeosporioides \\
North Florida & Gainesville & Store A & $2 / 2012$ & 2 & C. dracaenophilum \\
North Florida & Gainesville & Store B & $3 / 2012$ & 3 & C. dracaenophilum \\
North Florida & Gainesville & Store A & $4 / 2013$ & 4 & C. dracaenophilum \\
North Florida & Gainesville & Store B & $4 / 2013$ & 5 & C. dracaenophilum \\
\hline
\end{tabular}


bamboo plants by inserting a mycelial agar plug ( $5 \mathrm{~mm}$ in diameter) into a cut on the upper half of the stalk with a sterile blade. The negative control consisted of a similar plug of sterile acidified PDA agar. The inserted plugs were then covered with parafilm strips (Bobev et al., 2008). The inoculated and control plants of the first set of experiments was kept in a controlled growth chamber with a 12 -h photoperiod at $25^{\circ} \mathrm{C}$, and the second set of experiments was kept in a greenhouse with a 12 -h photoperiod at 25 to $30{ }^{\circ} \mathrm{C}$. The plants were watered daily with de-ionized water and fertilized with $20 \mathrm{~N}-$ $20 \mathrm{P}_{2} \mathrm{O}_{5}-20 \mathrm{~K}_{2} \mathrm{O}$ (J.R. Peters, Inc., Allentown, PA) once every 3 weeks. The experiments were arranged in a randomized complete block design with three replications and five pots with one plant each per treatment within each block. There were two repetitions of each experiment.

Plants were checked for symptom development weekly (first set of experiments) or daily (second set of experiments). In the first set of experiments, disease incidence was calculated weekly for 2 months. In the second set of experiments, disease severity was determined from the length and width of lesions with acervuli per plant, starting $6 \mathrm{~d}$ after inoculation and at 4-d intervals thereafter for 3 weeks. The diseased area per plant was calculated using the formula of an ellipse for each lesion. After the final assessments, stem tissues containing lesions and acervuli were disinfected with a $10 \%$ bleach solution and washed in de-ionized water. Symptomatic tissue was aseptically removed and transferred to acidified PDA plates. Plates were incubated for $6 \mathrm{~d}$ at $24^{\circ} \mathrm{C}$ and hyphal growth, shape, and size of conidia were examined for the presence of Colletotrichum using a compound microscope.

Latent infections. One hundred additional lucky bamboo cuttings were planted individually in greenhouse potting soil and kept in a separate greenhouse with a 12- to 13-h photoperiod at 25 to $30{ }^{\circ} \mathrm{C}$ to observe the latent presence of Colletotrichum spp. The plants were watered once every $3 \mathrm{~d}$ with deionized water and fertilized with $20 \mathrm{~N}-20 \mathrm{P}_{2} \mathrm{O}_{5}$ $20 \mathrm{~K}_{2} \mathrm{O}$ once every 3 weeks. The plants were assessed daily for symptom development for 3 months, and lucky bamboo plants with anthracnose were counted. This study was conducted three times (first with residual cuttings of the first set of pathogenicity experiments, second with cuttings of the second set of experiments, and third with cuttings of the fungicide trial) to provide an estimate of latent infections from separate sources.

DNA isolation and sequencing. After microscopic confirmation of Colletotrichum spores, genomic DNA was extracted from actively growing mycelium using a quick DNA extraction protocol (Smith et al., 2011). DNA from isolates 1,4 , and 5 were used for polymerase chain reaction (PCR), sequencing, and phylogenetic analyses. Both the ITS and the $28 \mathrm{~S}$ subunit of ribosomal DNA (rDNA) regions were amplified with PCR using primer pairs ITS1-F (5'-CTTGGTCATTTA
GAGGAAGTAA -3') plus ITS4 (5'-TCCT CCGCTTATTGATATGC $\left.-3^{\prime}\right)$ and LROR (5'-ACCCGCTGAACTTAAGC-3') plus LR5 (5' ${ }^{\prime}$ TCCT GAGGGAAACTTCG-3'), respectively (Vilgalys and Hester, 1990; White et al., 1990). The PCR master mix consisted of $10 \times$ buffer, $10 \mathrm{~mm}$ dNTPs, $25 \mathrm{~mm} \mathrm{MgCl}_{2}$, DNA polymerase, sterile distilled water, and $10 \mu \mathrm{M}$ of each primer. Initial denaturation was at $94{ }^{\circ} \mathrm{C}$ for 2 min with 39 cycles of denaturation at $94{ }^{\circ} \mathrm{C}$ for $30 \mathrm{~s}$, annealing at $54{ }^{\circ} \mathrm{C}$ (for primer pair ITS1-F and ITS4) or $50{ }^{\circ} \mathrm{C}$ for (primer pair LROR and LR5) for $30 \mathrm{~s}$, and elongation at $72^{\circ} \mathrm{C}$ for 1 min with a final elongation at $72{ }^{\circ} \mathrm{C}$ for $10 \mathrm{~min}$ (MyCycler Thermal Cycler; BioRad, Hercules, CA). Polymerase chain reaction products were cleaned using the Wizard SV Gel and PCR Clean-up System. Purified PCR products were submitted to the University of Florida Interdisciplinary Center for Biotechnology Research for DNA sequencing.

Isolate sequences were compared with ITS and 28S sequences from type cultures of Colletotrichum as described in Cannon et al. (2012). The sequence alignment used by Cannon and colleagues was downloaded from TreeBASE study S13170 and trimmed to include the ITS locus only. Initial species identification was obtained by aligning our ITS sequences with the trimmed Cannon alignment and constructing a Neighbor-joining tree in Geneious 6.16 (Biomatters Ltd.). Subsequently, 28S sequences for the type strain of $C$. dracaenophilum were downloaded from GenBank for comparison across the entire region.

Host range experiment. Three varieties of Dracaena marginata var. 'Tarzan', 'Magenta', and 'Colorama', and one variety of lucky bamboo obtained from Delray Plants Co., Venus, FL, and isolates 1, 4, and 5 were used for the host range experiment. Two inoculation methods were tested: drop and agar plug inoculation (Bobev et al., 2008; Than et al., 2008). A small cut was made in the upper half of the stalk by using a sterile blade. A drop of $20 \mu \mathrm{L}$ of a conidial suspension $(1 \times$ $10^{7}$ conidia $/ \mathrm{mL}$ ) was placed in the cut and the wound was covered with parafilm. Agar plug inoculation was performed as described previously (Bobev et al., 2008). Control plants were inoculated either with sterile water or sterile acidified PDA agar plugs. Inoculated cuttings were planted individually in $10-\mathrm{cm}$ diameter pots containing potting mix and maintained in a greenhouse with a 12-h photoperiod at 25 to $30{ }^{\circ} \mathrm{C}$ as described previously. The experiment was arranged in a randomized complete block design with four replications (plants) per treatment. There were two repetitions of the experiment.

Heat treatment experiments. Three independent hot water treatment experiments were conducted with non-inoculated rooted lucky bamboo cuttings. The purpose was to investigate if anthracnose symptoms would appear on imported symptomless lucky bamboo plants and if such symptoms could be suppressed by a heat treatment. In the first experiment, 10 rooted cuttings $(10 \mathrm{~cm}$ long) were soaked in a hot water bath at $47{ }^{\circ} \mathrm{C}$ for $15 \mathrm{~min}$ and 10 similar cuttings were left in a water bath at room temperature $\left(24^{\circ} \mathrm{C}\right)$ for $15 \mathrm{~min}$. Treated cuttings were planted in potting mix in 10-cm-diameter pots and kept, completely randomized, in a temperatureand light-controlled growth chamber at $25{ }^{\circ} \mathrm{C}$ with a 12 -h photoperiod. In a second experiment, four $10-\mathrm{cm}$-long non-inoculated lucky bamboo plants were treated in a water bath at $24,45,50$, or $55{ }^{\circ} \mathrm{C}$ for $15 \mathrm{~min}$. Treated cuttings were planted in $10-\mathrm{cm}$ diameter pots and kept in a growth chamber as described previously. The experimental design was a randomized block design with two blocks and two pseudo-replications, resulting in four plants per treatment. In a third experiment, 100 non-inoculated lucky bamboo cuttings were treated in a water bath at $47^{\circ} \mathrm{C}$ for $15 \mathrm{~min}$ and 47 plants were left in a water bath at $24^{\circ} \mathrm{C}$ for $15 \mathrm{~min}$. The treated cuttings were planted in potting soil and kept in a greenhouse at 25 to $30{ }^{\circ} \mathrm{C}$ with a $14-\mathrm{h}$ photoperiod.

Fungicide experiment. Systemic fungicides, Bayleton ${ }^{\circledR}$ (Triadimefon 50\%, $0.075 \mathrm{~g}$ a.i./L of water; Bayer Environmental Science, Research Triangle Park, NC) and Heritage (Azoxystrobin $50 \%, 0.075 \mathrm{~g}$ a.i./L of water; Syngenta Crop Protection, Greensboro, NC), were tested for preventive and curative control of anthranose on lucky bamboo. Rooted cuttings of lucky bamboo were sprayed using a hand sprayer until runoff and were kept in containers with water $(1 \mathrm{~cm}$ deep) until inoculation. Control plants were sprayed with sterile water in a similar way and kept in separate containers to avoid contamination.

Plants were inoculated by inserting a mycelial agar plug ( $5 \mathrm{~mm}$ in diameter) into a cut on the upper half of the stalk $24 \mathrm{~h}$ after spraying with the fungicide, planted individually in 10-cm-diameter pots, and maintained in a greenhouse as described previously. There were six treatments: 1) Triadimefon plus mock inoculation with a sterile agar plug; 2) Triadimefon plus inoculation with $C$. dracaenophilum isolate 4; 3) Azoxystrobin plus mock inoculation,;4) Azoxystrobin plus inoculation with $C$. dracaenophilum isolate $4 ; 5)$ no-fungicide control plus inoculation with $C$. dracaenophilum isolate 4 ; and 6) nofungicide control with mock inoculation. The experiment was arranged in a randomized complete block design with four replications (five plants per replication) per treatment. There were two repetitions of the experiment. Plants were checked for symptom development daily, and the length and width of lesions were measured on each plant when typical acervuli were present. The plants were assessed at 4-d intervals from 6 to $23 \mathrm{~d}$ after inoculation. The diseased area per plant was calculated using the formula for an ellipse. After final disease assessment, plants sprayed with fungicide but noninoculated (Triadimefon or Azoxystrobin plus mock inoculation) or sprayed with water but mock-inoculated were left in the greenhouse for 2 more months to determine whether disease would develop from asymptomatic plants and to control if 
the fungicides had a curative effect on Colletotrichum spp.

Statistical analysis. Disease incidence in the first pathogenicity tests was compared for plants treated with one of the three Colletotrichum isolates (isolates 1,2, and 3) or sterile agar using a $\chi^{2}$ test in Microsoft Excel (Microsoft Inc., Redmond, WA). An additional $\chi^{2}$ test was performed to compare disease incidence on plants treated with the two putative $C$. dracaenophilum isolates (isolates 2 and 3). Areas under the disease progress curve (AUDPC) were calculated for each of three replications of isolates 2 and 3. Analysis of variance (PROC GLM, SAS software Version 9.2; SAS Institute Inc., Cary, NC) was used to determine whether significant differences existed between the isolates in AUDPC values. Areas under the disease progress curve values were also calculated per block for the disease severity measurements of the second set of pathogenicity tests, the host range tests, and the fungicide experiment. Areas under the disease progress curve values were compared with a generalized linear model analysis of variance (ANOVA) using SAS statistical software. Data of each experiment were tested for normality using the Shapiro-Wilk test of residuals and checked for outliers using Lund's test of standardized residuals (Lund, 1975). No outliers were found in any data set. There were no effects of repetition or repetitiontreatment interactions; therefore, the data of the repeated experiments were analyzed together. Linear regression analysis without intercept was used to quantify the relationship between diseased area and days after inoculation for different fungicide treatments and blocks. Estimates for the slope were compared with a generalized linear model ANOVA. Means were separated using Tukey's test. Finally, $\chi^{2}$ tests were performed to compare disease incidence on non-inoculated lucky bamboo stems that were exposed to different heat treatments.

\section{Results}

Isolations from lucky bamboo. One Colletotrichum strain was isolated from symptomatic stalk tissue on lucky bamboo obtained from an ornamental plant producer in southern Florida in 2011 (isolate 1). Salmon-colored spores and waxy, subepidermal acervuli, typically with setae and simple, short, erect conidiophores, were observed in lesion centers. Colonies of isolates on PDA produced abundant conidia that were hyaline, onecelled, straight, cylindrical, and averaged $14.7 \times 5.0 \mu \mathrm{m}$ with ranges of 12.5 to $17.5 \times$ 3.8 to $7.5 \mu \mathrm{m}$. Cultural and morphological characteristics of isolates matched those for the Colletotrichum gloeosporioides species complex (Penz.) Penz. \& Sacc.

Two Colletotrichum strains were isolated from symptomatic lucky bamboo stems in 2012 (isolates 2 and 3 ) and two (isolates 4 and 5) from symptomatic lucky bamboo in 2013. Lesions were beige to light brown surrounded by a purple to dark brown border. Acervuli on the surface of the lesions were black. Setae were sparse and conidia were cylindrical, straight, or slightly curved (Fig. 1b). Colonies of isolates 2, 3, 4, and 5 on acidified PDA were white and became pale pink in the center of each colony (Fig. 2a-b). They were putatively considered to be $C$. dracaenophilum based on the colony color and morphology and microscopic observation of the conidia and setae. The colonies of all strains on acidified PDA produced abundant conidia that were hyaline, one-celled, and cylindrical. The size of the conidia was the same irrespective of store and year of collection. Conidia of isolates 2, 3, 4, and 5 averaged $13.3 \times 4.05 \mu \mathrm{m}$ with ranges of 11.5 to $14.5 \times$ 3.9 to $4.2 \mu \mathrm{m}$.

Pathogenicity test and re-isolation. In the first set of pathogenicity tests, anthracnose symptoms developed slowly on lucky bamboo inoculated with isolates 2 and 3 of putative $C$. dracaenophilum from stores $\mathrm{A}$ and $\mathrm{B}$ in north Florida. Two to 3 weeks after inoculation, light brown lesions with purple to dark brown margins developed on several of the inoculated plants, spreading out from the inoculation location (Table 2). At 3 weeks, acervuli appeared. No symptoms were observed on plants inoculated with the isolate of the $C$. gloeosporioides species complex (isolate 1) from south Florida or on the non-inoculated control plants. Chi square analysis of the disease incidence data indicated that $15 \mathrm{~d}$ after inoculation, no significant difference existed in disease incidence between isolates 2 and 3 from stores $A$ and $\mathrm{B}$, respectively. However, for all subsequent time points, isolate 3 from store B exhibited a significantly higher incidence of disease than isolate 2 from store A (Table 2). Consequently, isolate 3 had a significantly $(P=0.03)$ larger AUDPC value than isolate 2 .

In the second set of pathogenicity tests, typical anthracnose symptoms were observed on all lucky bamboo plants inoculated with Colletotrichum spp., but no symptoms were found on control plants during the whole assessment period ( $22 \mathrm{~d}$ ). Isolates 4 and 5 from stores $\mathrm{A}$ and $\mathrm{B}$, respectively, had a similar pattern of disease development (Fig. 3). Disease symptoms consisted of light brown lesions surrounded by a dark brown border, spread from the area of the stem that had been inoculated. Dark brown acervuli first appeared $6 \mathrm{~d}$ after inoculation, and disease developed gradually on isolates 4 and 5. Plants inoculated with isolates 4 and 5 had $0.28 \mathrm{~cm}^{2}$ and $0.14 \mathrm{~cm}^{2}$ diseased area on Day 6 , and diseased area increased slowly to 2.7 and $2.2 \mathrm{~cm}^{2}$ on Day 14 and $7.4 \mathrm{~cm}^{2}$ and $6.2 \mathrm{~cm}^{2}$ on Day 22, respectively.

Colletotrichum strains re-isolated by plating acervuli from infected tissues onto acidified PDA after inoculation with the four isolates from stores $\mathrm{A}$ and $\mathrm{B}$ had similar colonies, setae, and shape and size of conidia as observed for the initial isolates.

Latent infections. The latent infection varied among different batches from the same source. In the first set, of the 100 lucky bamboo cuttings that were planted in individual pots in
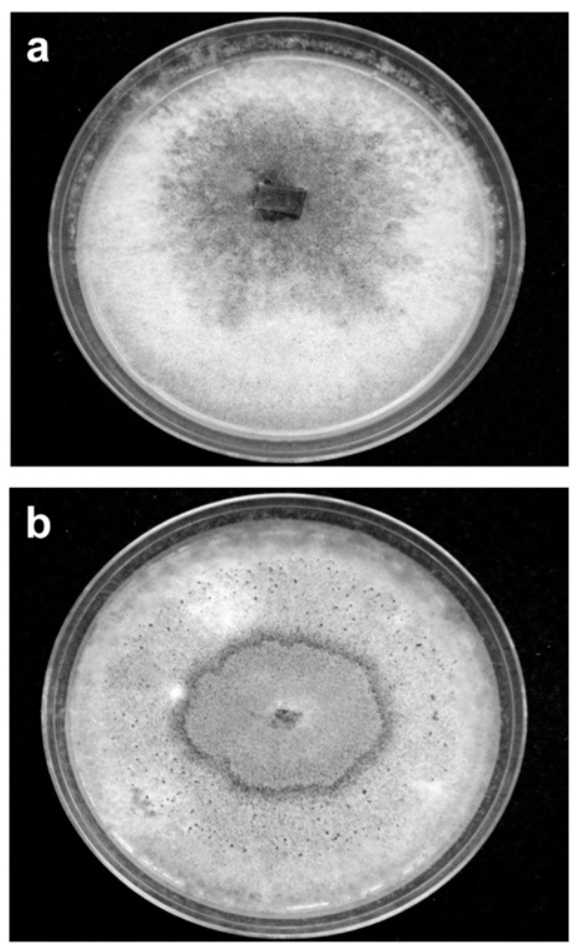

Fig. 2. Variation in colony color and morphology among the cultures of isolates 4 and 5 of Collectotrichum sp. that were isolated from lucky bamboo from stores A (a) and B (b) in Apr. 2013 in Gainesville, FL.

Table 2. Number of lucky bamboo plants with or without symptoms of anthracnose disease out of 15 plants inoculated with one isolate of the Colletotrichum gloeosporioides species complex (isolate 1) that was collected in 2011 in Miami, two isolates of Colletotrichum dracaenophilum (isolates 2 and 3) that were collected in 2012 in Gainesville, or water as a control treatment, 15, 20, and $28 \mathrm{~d}$ after inoculation (DAI). ${ }^{\mathrm{z}}$

\begin{tabular}{|c|c|c|c|c|c|c|c|c|c|}
\hline \multirow[b]{2}{*}{ Treatment } & \multicolumn{3}{|c|}{$15 \mathrm{DAI}$} & \multicolumn{3}{|c|}{$20 \mathrm{DAI}$} & \multicolumn{3}{|c|}{$28 \mathrm{DAI}$} \\
\hline & Disease & No disease & $\chi^{2}$ & Disease & No disease & $\chi^{2}$ & Disease & No disease & $\chi^{2}$ \\
\hline Isolate 2 & 1 & 14 & 24 & 1 & 14 & 23 & 8 & 7 & 44 \\
\hline Isolate 3 & 6 & 9 & & 8 & 7 & & 15 & 0 & \\
\hline Isolate 1 & 0 & 15 & & 0 & 15 & & 0 & 15 & \\
\hline Water & 0 & 15 & & 0 & 15 & & 0 & 15 & \\
\hline Isolate 2 & 1 & 14 & 4.6 & 1 & 14 & 7.7 & 8 & 7 & \\
\hline Isolate 3 & 6 & 19 & & 8 & 7 & & 15 & 0 & \\
\hline
\end{tabular}

${ }^{\mathrm{z}}$ Chi square tests to compare disease incidence among all treatments for all three blocks together were significant at $P<0.025$, df $=3$. Chi square tests to compare disease incidence between the two $C$. dracaenophilum isolates were significant at $P<0.025$, $\mathrm{df}=1$, when $\chi^{2}>5.02$. 
a greenhouse, 5\% developed typical anthracnose symptoms after 2 months. The incidence increased gradually to $25 \%$ in 3 months. In the second and third sets, $7 \%$ and $10 \%$ of the plants developed typical anthracnose symptoms after 1 month, $18 \%$ and $20 \%$ after 2 months, and $40 \%$ and $43 \%$, respectively, after 3 months.

DNA sequencing. Colletotrichum isolates 2, 3, 4, and 5 from stores A and B had identical ITS and $28 \mathrm{~S}$ sequences to ex-holotype $C$. dracaenophilum CBS 118199 based on comparison with GenBank accessions DQ286209 and DQ286210. Colletotrichum isolate 1 from

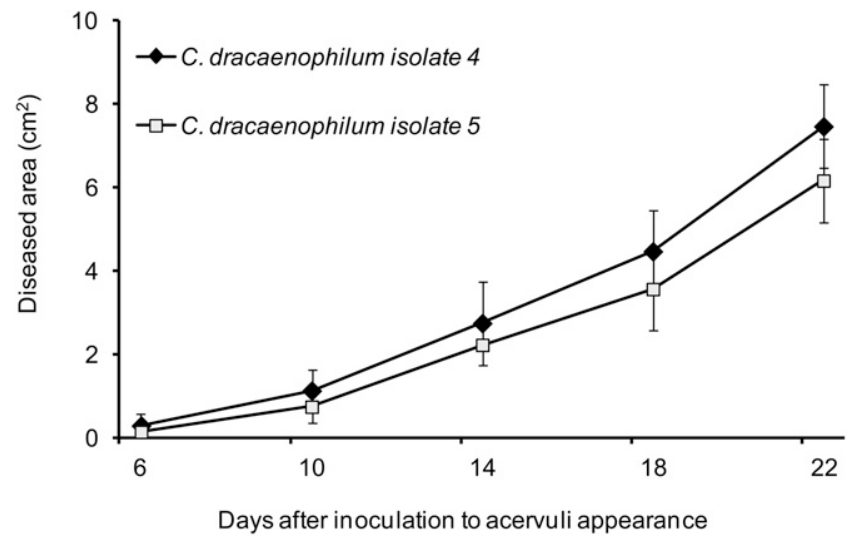

Fig. 3. Pathogenicity test on lucky bamboo of single spore isolates of Collectotrichum dracaenophilum that were isolated from store A (isolate 4) and B (isolate 5) in 2013 in Gainesville, FL.
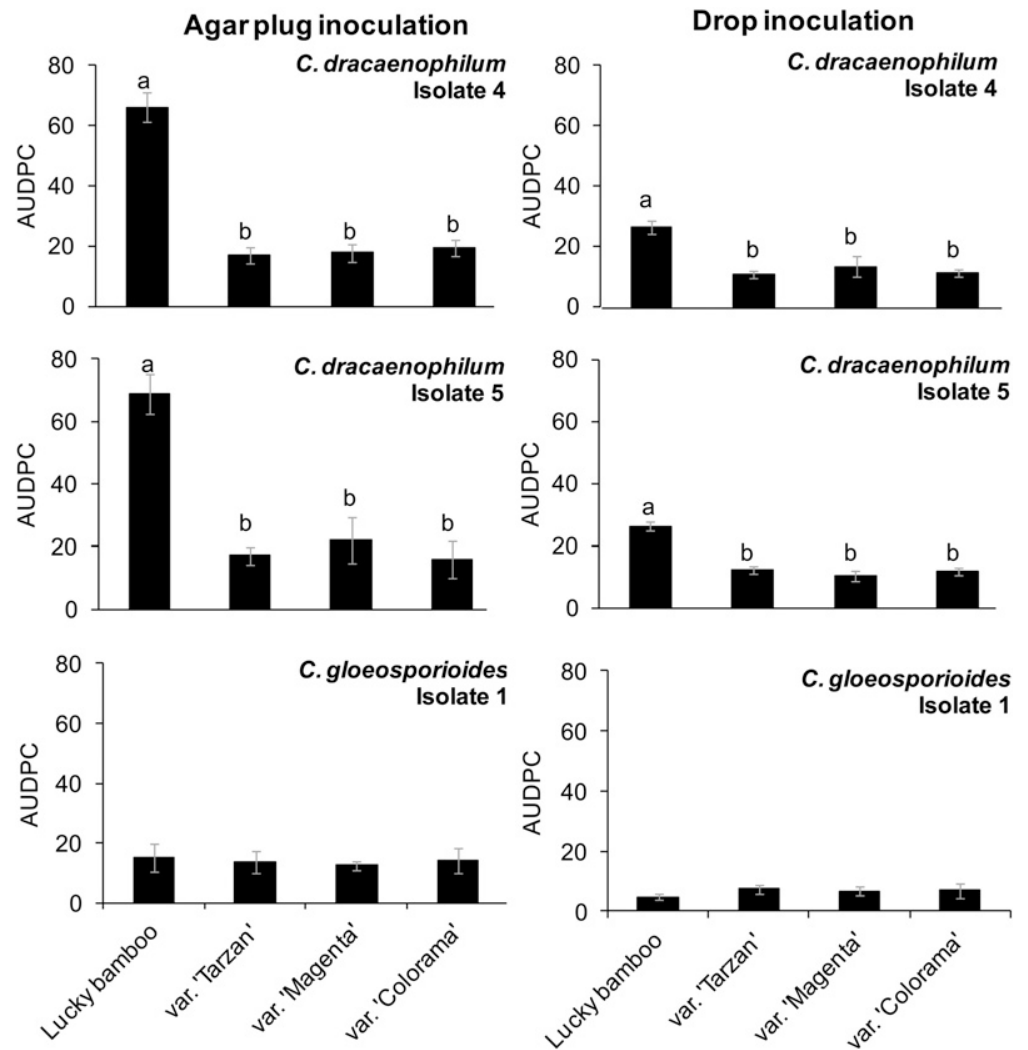

Fig. 4. Comparisons of agar plug and drop inoculation methods with C. dracaenophilum isolates 4 and 5 , and isolate 1 of the $C$. gloeosporioides species complex with respect to areas under the disease progress curves on lucky bamboo and Dracaena marginata varieties. Data are the means \pm SD of two repetitions of the study, each with four replications (one plant per replication). Significant differences are marked with different letters above bars $(P \leq 0.05$, Tukey test). gloeosporioides species complex. None of the varieties were resistant to the tested isolates of Colletotrichum spp. The mean diseased areas were highest on lucky bamboo, whereas Dracaena marginata varieties 'Tarzan', 'Magenta', and 'Colorama' had similar responses to inoculation with the Colletotrichum spp. but lower than lucky bamboo. A significant $(\mathrm{F}$ value $=24.9, P<0.0001)$ varietyisolate interaction occurred for AUDPC between the host plant and Colletotrichum isolate in the ANOVA (Fig. 4). Lucky bamboo was more susceptible to the $C$. dracaenophilum isolates than the isolate of the $C$. gloeosporioides species complex. No differences existed in response of the tested Dracaena species and varieties to this last isolate.

Heat treatment. All of the lucky bamboo plants treated at 50 and $55^{\circ} \mathrm{C}$ died $\approx 1$ week after treatment. Therefore, only plants treated at $24{ }^{\circ} \mathrm{C}$ and at $47^{\circ} \mathrm{C}$ were compared in a $\chi^{2}$ test where the data from all three tests were combined. Of a total of 61 non-inoculated plants that were kept in a water bath at $24{ }^{\circ} \mathrm{C}$ for $15 \mathrm{~min}$, five plants developed symptoms of anthracnose disease. Of a total of 114 noninoculated plants kept in the $47{ }^{\circ} \mathrm{C}$ water bath, 24 plants developed symptoms of anthracnose. Significantly $(P<0.025)$ more plants treated at $47^{\circ} \mathrm{C}$ became diseased than plants kept at $24{ }^{\circ} \mathrm{C}(21 \%$ of the plants at $47{ }^{\circ} \mathrm{C}$ vs. $8 \%$ at $24{ }^{\circ} \mathrm{C}$ ).

Fungicide experiment. Mock-inoculated plants did not develop anthracnose symptoms within the assessment period ( $22 \mathrm{~d}$ ) of this experiment. The inoculated lucky bamboo plants without fungicide developed higher disease severity than plants treated with Azoxystrobin and Triadimefon (Fig. 5). The increase in diseased area was linear over time. The slope of the regression line was higher on inoculated plants without fungicide and on inoculated plants treated with Triadimefon than on those treated with Azoxystrobin (slope $=0.22$ and 0.15 vs. $0.04 \mathrm{~cm}^{2} \cdot \mathrm{d}^{-1}$, respectively). Spraying inoculated plants with Azoxystrobin reduced the final disease incidence $\approx 50 \%$ as compared with inoculated plants treated with Triadimefon or water (Fig. 6). The mean AUDPC was reduced more by Azoxystrobin than by Triadimefon (AUDPC $=6 \mathrm{vs} .33 \mathrm{~cm}^{2} \cdot \mathrm{d}^{-1}$ ).

Some of the mock-inoculated plants that were left in the greenhouse for 2 months after the final assessment developed anthracnose symptoms. Overall, the mock-inoculated plants treated with water had a higher proportion of diseased plants [ 15 of 40 plants (37\%)] than mock-inoculated plants treated with Triadimefon 50 [four of 40 plants $(10 \%)$ ]. In contrast, mock-inoculated plants treated with Azoxystrobin did not develop disease supporting the hypothesis that Azoxystrobin has a curative effect on latent infection by $C$. dracaenophilum on lucky bamboo.

\section{Discussion}

The most important finding in this study was that two different Colletotrichum species (C. dracaenophilum and a member of the $C$. 


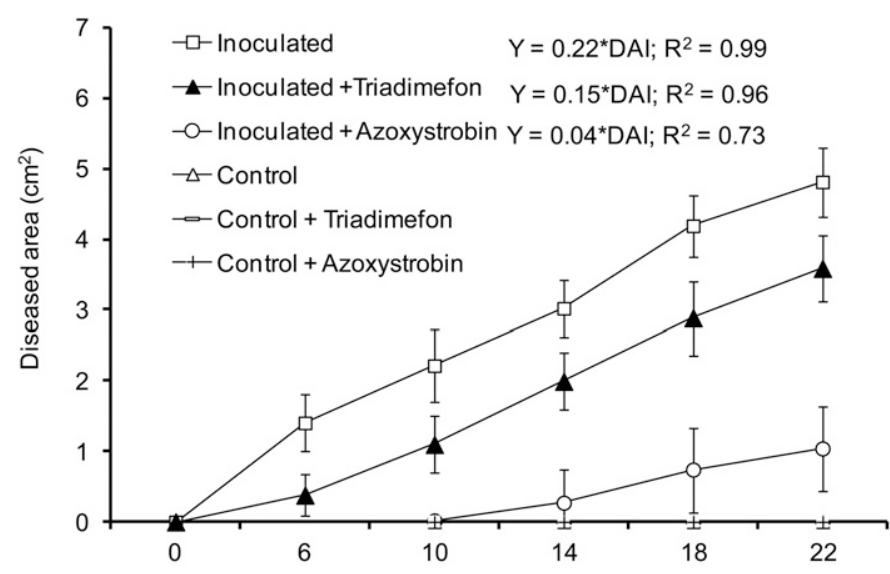

Days after inoculation to acervuli appearance

Fig. 5. Effect of Triadimefon 50 and Azoxystrobin on diseased area $\left(\mathrm{cm}^{2}\right)$ of Collectotrichum dracaenophilum isolate 4 over time. Data are the means \pm SD of two repetitions of the study, each with four replications (five plants per replication).

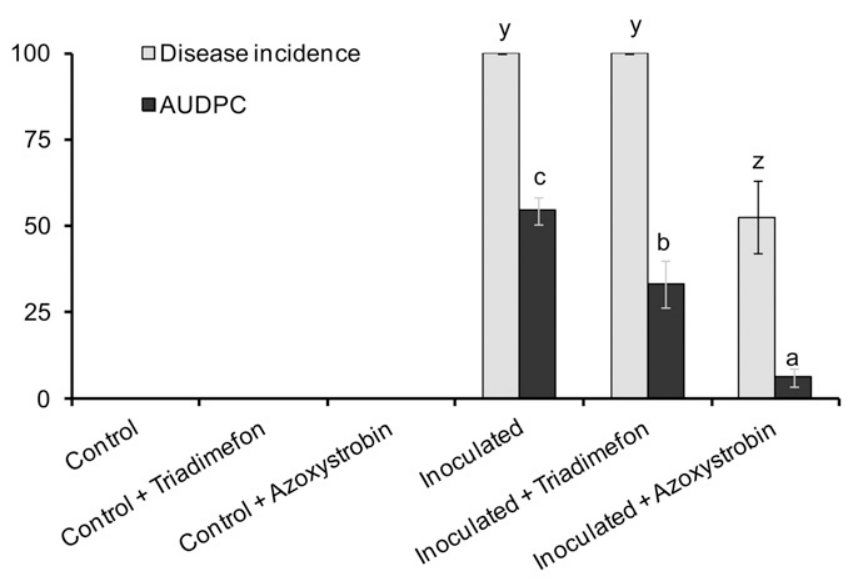

Treatments

Fig. 6. Effect of Triadimefon 50 and Azoxystrobin on disease incidence (\%) and area under disease progress curve (AUDPC) of Collectotrichum dracaenophilum isolate 4 after $22 \mathrm{~d}$. Data are the means \pm SD of two repetitions of the study, each with four replications (five plants per replication). Significant differences are marked with different letters above bars $(P \leq 0.05$, Tukey test $)$.

gloeosporioides species complex) were isolated from Dracaena sanderiana with anthracnose in Florida and that both species were pathogenic to lucky bamboo. All strains were re-isolated from inoculated lucky bamboo, thereby fulfilling the requirements for Koch's postulates. Sequencing results indicated that two Colletotrichum isolates from lucky bamboo in north Florida were $C$. $d r a-$ caenophilum, whereas the south Florida isolate was confirmed to be in the $C$. gloeosporioides species complex (Cannon et al., 2012). The C. dracaenophilum strains isolated from lucky bamboo caused more severe disease on lucky bamboo than on D. marginata varieties, whereas the isolate of the C. gloeosporioides species complex was only weakly pathogenic on all species and varieties as observed previously (Phoulivong et al., 2012). Thus, the member of the C. gloeosporioides species complex found on lucky bamboo in south Florida may have been present incidentally when a susceptible ornamental plant was grown in the same greenhouse (Phoulivong et al., 2012). Further characterization of the variation in aggressiveness of different strains and the relative susceptibility of different Dracaena species and cultivars would be helpful in developing a systems approach to disease management (Parke and Grunwald, 2012).

Faster disease development in the greenhouse experiments with isolates 4 and 5 compared with that in the growth chamber with isolates 2 and 3 of $C$. dracaenophilum suggests that the higher temperatures in the greenhouse might have accelerated disease development. This is in agreement with the increase in lesion size of cucumber anthracnose caused by Colletotrichum lagenarium (Thompson and Jenkins, 1985) and of lentil anthracnose caused by $C$. truncatum at higher temperatures (Chongo and Bernier, 2000). Increasing the temperature from 25 to $30{ }^{\circ} \mathrm{C}$ may have rendered the plants more susceptible or the Colletotrichum strain may have been more virulent at higher temperatures.

Another important finding in this study was that seemingly healthy rooted cuttings of lucky bamboo introduced from China may carry $C$. dracaenophilum, which can induce anthracnose symptoms several months after arrival in the United States. It is not currently known which environmental factors may trigger the appearance of symptoms. However, in this study, lesions appeared on noninoculated stalks when irrigation intervals were lengthened. Thus, water stress may trigger the induction of symptoms. This was also reported for other Colletotrichum spp. (Roberts et al., 2012). In addition, high temperatures may lead to enhanced symptom expression, as demonstrated for heat-treated cuttings in a water bath at $47^{\circ} \mathrm{C}$ for $15 \mathrm{~min}$ in this study.

Considering the latent presence of $C$. dracaenophilum in lucky bamboo imported from China $(25 \%$ to $43 \%$ of all noninoculated stalks included in the latent infection study), it is important that nursery managers in the United States be trained to recognize the symptoms of $C$. dracaenophilum infections and to immediately remove plants with anthracnose lesions. In addition, nurseries producing rooted cuttings of lucky bamboo in China should also be trained to recognize this disease and remove any infected material from the production line. An effective approach to reach this goal is the so-called farmer field school approach (Mancini et al., 2008). This would contribute to a systems approach to disease management on lucky bamboo (Parke and Grunwald, 2012). In addition, it is important to develop techniques that allow detection of latent infections of Colletotrichum species in imported Dracaena cuttings. However, current molecular techniques such as real-time PCR are often not sensitive enough to detect a sporadic pathogen in asymptomatic tissues (Daugovish et al., 2012; Klerks et al., 2006).

In addition to timely detection of anthracnose infections, control methods need to be developed to eliminate latent infections. The hot water treatments tested were not promising for the control of $C$. dracaenophilum latently present in lucky bamboo. In this study, we tested only the classical hot water treatment. There may be other temperaturetime combinations that would hamper Colletotrichum without affecting plant susceptibility to this pathogen. Recently, short-duration high-temperature treatments proved to be effective at controlling various seedborne diseases (Daughtrey and Benson, 2005). In addition, machinery has been developed that can treat plant materials with aerated steam instead of hot water (Amein et al., 2011). This method was very effective at controlling seedborne pathogens and could be tested for controlling anthracnose on lucky bamboo.

Application of the systemic fungicide Azoxystrobin was effective both at preventing new infections by $C$. dracaenophilum and curing latent infections and anthracnose development on lucky bamboo plants. Approximately 
$37 \%$ of mock-inoculated lucky bamboo plants that were not treated with fungicide developed anthracnose apparently 3 months after initiation of the fungicide experiment, whereas similar plants treated with Azoxystrobin did not develop any disease. This fungicide was also effective at controlling $C$. acutatum on strawberry planting materials (Daugovish et al., 2009). Application of Triadimefon was less effective for the control of $C$. dracaenophilum. To limit the spread of $C$. dracaenophilum from infected rooted cuttings to healthy lucky bamboo plants, applications of a synthetic or natural fungicide might be useful (Cao and van Bruggen, 2001). Although various fungicides are known to be effective at controlling Colletotrichum spp. on a variety of hosts (Daugovish et al., 2009; Rampersad and Teelucksingh, 2012), this is the first attempt to test fungicides for the control of $C$. dracaenophilum on lucky bamboo. In ornamental greenhouses, fungicide applications may only be needed if overhead irrigation is used, because spore release and transmission from Colletotricum acervuli takes place by splash dispersal (Daugovish et al., 2012; Madden et al., 1996).

In conclusion, lucky bamboo introduced from China commonly carries a latent infection of the fungal pathogen $C$. dracaenophilum. Cuttings of other Dracaena species may be infected by a variety of Colletotrichum species. A whole systems approach is needed to address this problem. This approach includes 1) training and disease management at the source; 2) careful inspection at the ports of entry, if possible with random testing of pathogen presence using molecular techniques; 3 ) fungicide treatment of rooted cuttings to eliminate latent infection; and 4) training and disease management in lucky bamboo nurseries in destination countries.

\section{Literature Cited}

Alfieri, S.A., K.R. Langdon, J.W. Kimbrough, N.E. El-Gholl, and C. Wehlburg. 1994. Diseases and disorders of plants in Florida, Bulletin No. 14. Florida Department of Agriculture and Consumer Services, Division of Plant Industry.

Amein, T., S. Al. Wright, M. Wikstrom, E. Kock, A. Schmitt, D. Stephan, M. Jahn, F. Tinivella, M.L. Gullino, G. Forsberg, S. Werner, J. van der Wolf, and S.P. Groot. 2011. Evaluation of non-chemical seed treatment methods for control of Alternaria brassicicola on cabbage Seeds. J. Plant Dis. Prot. 118:214-221.

Bobev, S.G., L.A. Castlebury, and A.Y. Rossman. 2008. First report of Colletotrichum dracaenophilum on Dracaena sanderiana in Bulgaria. Plant Dis. 92:173.

Buck, J.W. and Y. Ono. 2012. Daylily rust. The Plant Health Instructor. 20 Mar. 2014. <https:// www.apsnet.org/edcenter/intropp/lessons/fungi/ Basidiomycetes/Pages/DaylilyRust.aspx>
Cannon, P.F., U. Damm, P.R. Johnston, and B.S. Weir. 2012. Colletotrichum-Current status and future directions. Stud. Mycol. 73:181-213.

Cao, K.Q. and A.H.C. van Bruggen. 2001. Inhibitory efficacy of several plant extracts and plant products on Phytophthora infestans. J. Agr. Univ. Hebei 24:90-96.

Chongo, G. and C.C. Bernier. 2000. Effects of host, inoculum concentration, wetness duration, growth stage, and temperature on anthracnose of lentil. Plant Dis. 84:544-548.

Clear, R.M., S.K. Patrick, T.K. Turkington, and R. Wallis. 2002. Effect of dry heat treatment on seed-borne Fusarium graminearum and other cereal pathogens. Can. J. Plant Pathol. 24:489498.

Customs and Border Patrol. 2012. Actionable disease found on plants from Canada. U.S. Customs and Border Patrol, Office of Field Operations, Agriculture Programs and Trade Liaison. Agriculture Enforcement Alert, Reference number AEA3004PD03242012.

Daughtrey, M.L. and D.M. Benson. 2005. Principles of plant health management for ornamenta plants. Annu. Rev. Phytopathol. 43:141-169.

Daughtrey, M.L. and A.R. Chase. 1992. Ball field guide to diseases of greenhouse ornamentals. Ball Publishing, Batavia, IL.

Daugovish, O., M. Bolda, S. Kaur, M.J. Mochizuki, D. Marcum, and L. Epstein. 2012. Drip irrigation in California strawberry nurseries to reduce the incidence of Colletotrichum acutatum in fruit production. HortScience 47:368-373.

Daugovish, O., H. Su, and W.D. Gubler. 2009. Preplant fungicide dips of strawberry transplants to control anthracnose caused by Colletotrichum acutatum in California. HortTechnology 19:317-323.

du Toit, L.J. and P. Hernandez-Perez. 2005. Efficacy of hot water and chlorine for eradication of Cladosporium variabile, Stemphylium botryosum, and Verticillium dahliae from spinach seed. Plant Dis. 89:1305-1312.

Klerks, M.M., A.H.C. van Bruggen, C. Zijlstra, M. Donnikov, and R. de Vos. 2006. Comparison of methods of extracting Salmonella enterica serovar Enteritidis DNA from environmental substrates and quantification of organisms by using a general internal procedural control. Appl. Environ. Microbiol. 72:3879-3886.

Liebhold, A.M., E.G. Brockerhoff, L.J. Garrett, J.L. Parkeand, and O.K. Britton. 2012. Live plant imports: The major pathway for forest insect and pathogen invasions of the U.S. Front. Ecol. Environ. 10:135-143.

Lund, R.E. 1975. Tables for an approximate test for outliers in linear models. Techometrics 17: 473-476.

Madden, L.V., X. Yang, and L.L. Wilson. 1996. Effects of rain intensity on splash dispersal of Colletotrichum acutatum. Phytopathology 86:864-874.

Mancini, F., A.J. Termorshuizen, J.L.S. Jiggins, and A.H.C. van Bruggen. 2008. Increasing the environmental and social sustainability of cotton farming through farmer education in Andhra Pradesh, India. Agr. Syst. 96:16-25.

Merritt, J.L., E. Dickstein, R.S. Johnson, M. Ward, R.J. Balaam, C.L. Harmon, P.F. Harmon, G.S
Ali, A.J. Palmateer, T. Schubert, and A.H.C. van Bruggen. 2012. Survey of Ornamental Nurseries in Florida Participating in the U.S.Canadian Greenhouse Certification Program. HortTechnology 22:169-176.

Momol, T.M. 2006. Recovery plan for Ralstonia solanacearum Race 3 biovar 2, causing brown rot of potato and southern wilt of geranium. Online. National Plant Disease Recovery System (NPDRS), Dept. of Homeland Security, Washington, DC.

Parke, J.L. and N.J. Grunwald. 2012. A system approach for management of pests and pathogens of nursery crops. Plant Dis. 96:1236-1244.

Peres, N.A., L.W. Timmer, J.E. Adaskaveg, and J.C. Correll. 2005. Lifestyles of Colletotrichum acutatum. Plant Dis. 89:784-796.

Phoulivong, S., E.H.C. McKenzie, and K.D. Hyde. 2012. Cross infection of Colletotrichum species; a case study with tropical fruits. Curr. Res. Environ. Appl. Mycol. 2:99-111.

Prihastuti, H., L. Cai, H. Chan, E.H.C. McKenzie, and K.D. Hyde. 2009. Characterization of Colletotrichum species associated with coffee berries in northern Thailand. Fungal Divers. 39:89-109.

Rampersad, S.N. and L.D. Teelucksingh. 2012. Differential responses of Colletotrichum gloeosporioides and $C$. truncatum isolates from different hosts to multiple fungicides based on two assays. Plant Dis. 96:1526-1536.

Roberts, P.D., K.L. Pernezny, and T.A. Kucharek. 2012. Anthracnose on pepper in Florida. Florida Cooperative Extension Service. EDIS Extension Fact Sheet PP104. 20 Mar. 2014 $<$ http://edis.ifas.ufl.edu/PP104>.

Shivas, R.G. and Y.P. Tan. 2009. A taxonomic reassessment of Colletotrichum acutatum, introducing $C$. fioriniae comb. et stat. nov. and $C$. simmondsii sp. nov. Fungal Divers. 39:111122.

Smith, M.E., T.W. Henkel, M.C. Aime, A.K. Fremier, and R. Vilgalys. 2011. Ectomycorrhizal fungal diversity and community structure on three co-occurring leguminous canopy tree species in a Neotropical rainforest. New Phytol. 192:699-712.

Than, P.P., R. Jeewon, K.D. Hyde, S. Pongsupasamit, O. Mongkolporn, and P.W.J. Taylor. 2008. Characterization and pathogenicity of Colletotrichum species associated with anthracnose on chilli (Capsicum spp.) in Thailand. Plant Pathol. 57: 562-572.

Thompson, D.C. and S.F. Jenkins. 1985. Effect of temperature, moisture and cucumber resistance on lesion size and increase and conidial production by Colletotrichum lagenarium. Phytopathology 75:828-832.

Vilgalys, R. and M. Hester. 1990. Rapid genetic identification and mapping of enzymatically amplified ribosomal DNA from several Cryptococcus species. J. Bacteriol. 172:4238-4246.

White, T.J., T. Bruns, S. Lee, and J. Taylor. 1990. Amplification and direct sequencing of fungal ribosomal RNA genes for phylogenetics, $\mathrm{p}$. 315-322. In: Innis, M.A., D.H. Gelfand, J.J. Sninsky, and T.J. White (eds.). PCR protocols: A guide to methods and applications. Academic Press, San Diego, CA. 